\title{
O longo e o curto prazo na aprendizagem da matemática
}

\section{Long term and short term in mathematics learning}

\author{
Gérard Vergnaud $^{1}$
}

\begin{abstract}
RESUMO
"Longo prazo" refere-se a uma perspectiva de desenvolvimento: entre as primeiras competências adquiridas pelas crianças pequenas, aos cinco e seis anos, e aquelas adquiridas por apenas uma parte dos adolescentes de quinze anos, numerosas etapas e processos, filiações e rupturas são observadas. "Curto prazo" refere-se a situações suscetíveis de serem utilmente propostas aos alunos em um ou outro momento de seu desenvolvimento em função das competências já adquiridas ou parcialmente adquiridas, como também ao acompanhamento que delas o professor faz para facilitar e guiar aquele processo de aquisição. As estruturas aditivas, por exemplo, fornecem diversos casos em que certa categoria de raciocínio e a escolha de uma operação de adição ou de subtração são nitidamente mais delicadas do que em outros casos. Isto exige um arranjo específico, uma ajuda significativa do adulto e, eventualmente, uma representação simbólica original. O mesmo acontece com as estruturas multiplicativas, a geometria, a álgebra, e em outros domínios, afastados da matemática, como o da moral ou da compreensão de textos. O presente artigo limita-se a esse respeito ao exemplo da aprendizagem da matemática.

Palavras-chave: desenvolvimento de competências matemáticas; ensino e aprendizagem da matemática; estruturas aditivas e multiplicativas; representações matemáticas; campos conceituais.
\end{abstract}

\footnotetext{
ABSTRACT

"Long term" refers necessarily to a developmental perspective: between the first competencies acquired by young children, at the age of five or six, and

1 Universidade de Paris 8, França, CNRS (Centre Nationale des Recherches Scientifiques).
} 
those acquired by fifteen year-old adolescents (only part of them), there are several steps and processes: continuities and discontinuities can be observed along this development. "Short term" concerns situations that are likely to be offered to students, for them to learn, at some crucial moment of this development. It is therefore concerned by the discovery, even partially, of new properties by students, owing to the teacher's help in conducting and facilitating the acquisitions course. The additive structures, for example, provide many different situations in which a particular reasoning and the choice of an addition or subtraction operation are clearly more delicate than in other situations: a case that requires a specific scenario, the assistance from the adult and, eventually, an original symbolic representation. The same kind of phenomena takes place with multiplicative structures, geometry, algebra, and other domains, far from mathematics, like morals and text comprehension. The present article limits this discussion to the case of mathematics learning.

Keywords: development of mathematical competencies; mathematics teaching and learning; additive and multiplicative structures; mathematical representations; conceptual fields.

"Longo prazo" refere-se inevitavelmente a uma perspectiva de desenvolvimento: não é em alguns dias ou em algumas semanas que uma criança adquire uma competência nova ou compreende um conceito novo, mas, sim, ao longo de vários anos de escola e de experiência. É a esse processo que a teoria dos campos conceituais se refere. Entre as primeiras competências adquiridas pelas crianças de quatro ou cinco anos relativas ao espaço e aos raciocínios sobre grandezas, por exemplo, e as competências que ainda trazem dificuldades à parte dos adolescentes de quinze anos, observam-se numerosas etapas e processos, filiações e rupturas:

- filiações porque as competências novas apoiam-se, em parte, nas competências adquiridas antes;

- rupturas porque, às vezes, a tomada de consciência necessária à formação de uma nova competência exige que a criança deixe de lado ideias e formas de agir anteriores. Por vezes, mesmo, é preciso que ela as rejeite. Como sua própria denominação o indica, a teoria dos campos conceituais trata dos conteúdos conceituais da atividade; ela assume o lugar das teorias gerais do desenvolvimento postas em termos de estádios ou em termos de funções executivas (atenção, controle, memória de curto prazo). Não que essas teorias não façam sentido; porém, como não são suficientemente próximas dos conteúdos escolares, elas não são verdadeiramente operatórias no âmbito do ensino.

Por sua vez, "curto prazo" refere-se a situações suscetíveis de serem utilmente propostas aos alunos em um ou outro momento do seu desenvolvimento, em função de competências já adquiridas ou parcialmente adquiridas. Também 
concerne ao acompanhamento que delas o professor faz e que lhe dá condições para facilitar e guiar o processo da aquisição.

Foi no campo da aritmética básica que obtive a maior parte das minhas observações e reflexões sobre a progressiva complexidade das situações matemáticas; contudo, essa dupla escala de tempo, de longo prazo e de curto prazo, é igualmente válida para a álgebra e a geometria. Aliás, ela vale também para outras disciplinas e outros domínios da atividade.

A tese subjacente a esta proposta teórica é a que o conteúdo conceitual específico das situações, dos enunciados e das representações simbólicas permite melhor captar as filiações e as rupturas.

\section{O caso exemplar das estruturas aditivas}

O campo conceitual das estruturas aditivas fornece numerosos exemplos de situações, nas quais a escolha de uma operação e a dos dados sobre os quais ela se aplica é delicada, exigindo um arranjo específico, uma ajuda significativa do adulto, eventualmente, uma representação simbólica original.

Existem duas situações prototípicas de adição, pelas quais as crianças dão um primeiro sentido a essa operação:

- a reunião de duas partes em um todo: "Três meninas e quatro meninos

estão em uma festa de aniversário. Ao todo, quantas crianças são?”.

- a transformação de uma quantidade inicial: "Pedro tinha $\mathrm{R} \$ 5,00$; sua

avó lhe deu R\$2,00. Quantos reais ele tem agora?".

Pode-se passar da primeira conceitualização prototípica à segunda, e reciprocamente; porém, a primeira oferece a possibilidade de um caso único de subtração (conhecendo-se o todo e uma das partes, encontrar a outra parte), enquanto a segunda oferece a possibilidade de quatro subtrações diferentes, a saber: a diminuição de uma quantidade inicial (protótipo da subtração); a busca por um aumento (estado final menos estado inicial); a busca por uma diminuição (estado inicial menos estado final); a busca de um estado inicial antes de um aumento (Joana acaba de ganhar $R \$ 3,00$ de sua avó; agora, ela tem $R \$ 8,00$. Quantos reais ela tinha antes de receber esse presente de sua avó?).

A transformação de uma quantidade inicial oferece ainda a possibilidade de uma adição não prototípica (Roberto acaba de gastar $R \$ 5,00$ e agora ele tem $R \$ 7,00$. Quanto ele tinha antes de comprar balinhas?).

A procura de um estado inicial é uma situação delicada para muitas 
crianças até o terceiro ano da escola elementar ${ }^{2}$ e mesmo adiante. Além de ser não prototípica, essa situação também esbarra no obstáculo representado pelo sentido da transformação direta, justamente derivado dos protótipos da adição e da subtração:

- o gasto de Roberto conduz a uma subtração e não a uma adição;

- o aumento da fortuna de Joana conduz a uma adição e não a uma subtração.

Para adotar a operação correta, é necessário um teorema-em-ato novo:

Se $F=T(I)$ então $I=T^{-1}(F)$

F estado final, I estado inicial, T transformação direta, $T^{11}$ transformação inversa.

A operação que permite passar do estado final ao estado inicial é inversa da que permite passar do estado inicial ao estado final.

Pode-se, então, formular várias sugestões para a intervenção dos professores, principalmente no caso dos primeiros anos da escola elementar:

- eles podem mostrar às crianças que é possível reagrupar e classificar as diferentes situações de adição e subtração relativas à transformação de um estado inicial em estado final;

- eles podem, para tanto, empregar um esquema com flechas que permite ligar os diferentes elementos da relação entre si.

Estado inicial

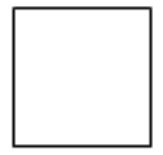

Transformação direta

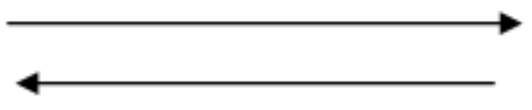

Transformação inversa
Estado final

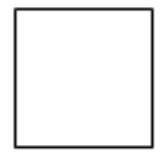

A rigor, o esquema acima não é indispensável para fazer com que as crianças compreendam os diversos componentes da relação, mas sua concisão permite ligar esses elementos entre si de imediato. Desse modo, o esquema fornece um complemento útil a explicações verbais e, sobretudo, permite captar o elo entre a transformação direta e a transformação inversa. Quando números são escritos nos lugares reservados aos estados e às transformações, pode-se ainda melhor apreciar as relações entre a adição e a subtração:

$$
\mathrm{T}=-5 \quad \mathrm{~F}=7 \quad \mathrm{~T}^{-1}=+5
$$

2 No sistema de ensino francês, o terceiro ano da escola elementar atende crianças de aproximadamente oito anos de idade. N. T. 

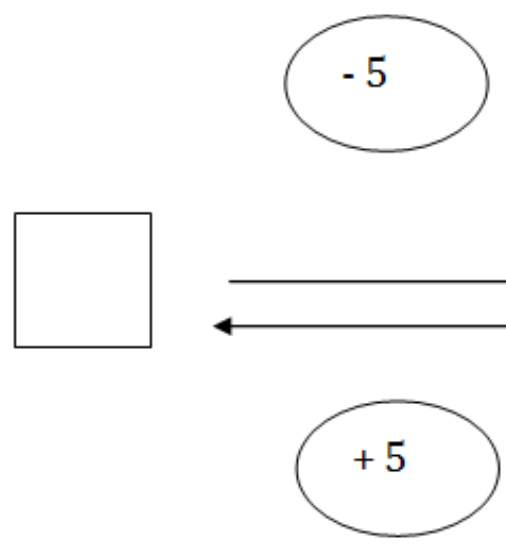

Uma última observação: a diferença entre transformações e estados, já indicada pelas formas do retângulo e da elipse, acompanha então a distinção entre números relativos (positivos e negativos) para as transformações e as operações, e números naturais (sem sinal) para os estados. Dessa forma, introduz-se às crianças uma representação pré-algébrica.

Um segundo exemplo, ainda referente às estruturas aditivas, interessa ao final da escola elementar e aos primeiros anos da escola secundária ${ }^{3}$ : a decomposição de uma transformação composta conhecida em duas transformações sucessivas, das quais uma é conhecida e outra desconhecida, como no exemplo seguinte:

Henrique jogou duas partidas de bolinhas de gude, uma pela manhã, outra à tarde. Ele não se lembra mais do que aconteceu pela manhã. À tarde, ele... (aqui, cabe uma primeira variável do enunciado). À noite, fazendo suas contas, ele percebe que tem... (a segunda variável do enunciado). O que aconteceu pela manhã? Henrique ganhou ou perdeu bolinhas de gude e quantas?

Manipulando-se os valores das duas variáveis do enunciado, pode-se observar fenômenos surpreendentes:

Ganha 6 pela manhã; ganha 15 ao todo. O problema é resolvido sem dificuldade.

Ganha 15 à tarde; ganha 6 ao todo. Já é caso sensivelmente mais complicado.

Perde 6 à tarde; perde 15 ao todo. É resolvido sem dificuldade.

3 No sistema de ensino francês, ao final da escola elementar os alunos têm ao redor de 10 anos de idade, e nos primeiros anos da escola secundária, eles têm entre 11 a 12 anos de idade. N. T. 
Perde 15 à tarde; perde 6 ao todo. É caso mais delicado.

Ganha 6 à tarde. Perde 15 ao todo. O problema ocasiona um fracasso quase geral ao final da escola elementar, e entre grande maioria de insucessos no início da escola secundária.

Ganha 15 à tarde; perde 6 ao todo. Da mesma forma, insucesso quase geral.

Perde 6 à tarde; ganha 15 ao todo. Idem ao caso anterior.

Perde 15 à tarde; ganha 6 ao todo. Idem ao caso anterior.

$\mathrm{O}$ insucesso massivo observado nos quatro últimos casos pode ser explicado pelo fato de que as duas variáveis do enunciado têm sinal contrário, de forma que é preciso fazer uma adição para encontrar a resposta, enquanto que a decomposição de um todo em duas partes evoca a ideia de subtração.

Poder-se-ia pensar que, depois de ter aprendido números relativos na escola secundária (no segundo e no terceiro ano) ${ }^{4}$, os alunos teriam mais sucesso. Mas, de fato, esse não é o caso. O obstáculo da primeira intuição não é facilmente removido.

A contrario, o sucesso massivo dos alunos nos casos em que a transformação total (ganho ou perda) é maior em valor absoluto do que o ganho ou a perda do período da tarde, explica-se justamente pelo fato de que os alunos não levam em conta o caráter positivo ou negativo das transformações. Tratam então do problema como uma situação parte/parte/todo comum (um todo de 15, uma parte de 6, outra parte é o complemento). Este lapso oportuno de sentido permite-lhe dar uma resposta aceitável.

No caso em que a transformação total é menor (em valor absoluto) que a transformação ocorrida à tarde, os alunos hesitam. Um outro lapso de sentido é então possível: conservar a parte correspondente à tarde como um estado inicial e a transformação total como um estado final, e calcular a resposta pela diferença.

As ideias de "longo prazo" e "curto prazo" são novamente pertinentes:

- a de "longo prazo" porque certos casos são resolvidos por alunos relativamente jovens, enquanto alunos de quinze anos e adultos fracassam diante de outros casos.

- a de "curto prazo" porque é ocasião para o professor mostrar, ao mesmo tempo, a proximidade entre os enunciados e as diferenças das operações de pensamento necessárias ao tratamento desses elementos.

4 No sistema de ensino francês, esses anos da escola secundária tendem alunos de 12 e 13 anos, aproximadamente. N. T. 


\section{Como introduzir a álgebra?}

A família das situações que acabamos de descrever rapidamente também permite mostrar a continuidade e a ruptura entre a aritmética e a álgebra. É possível, por exemplo, utilizar-se dos casos acima expostos para mostrar que as equações $\mathrm{x}+\mathrm{a}=\mathrm{b}$ podem representar situações algebricamente bem diferentes:

$\mathrm{x}+6=15 ; \quad \mathrm{x}+15=6 ; \quad \mathrm{x}-6=-15 ; \quad \mathrm{x}-6=+15 ;$ etc.

Evidentemente, este não é o único artifício que possibilita a introdução da álgebra. Se a álgebra é, antes de mais nada, uma ferramenta, e não de pronto um conjunto de objetos matemáticos (função, equação, variável, incógnita, polinômio, vetor, sistemas...) é razoável, e mesmo indispensável, introduzi-la como meio de resolver problemas, cuja solução não saber-se-ia obter sem a álgebra.

Um bom exemplo é o caso em que uma mesma quantidade é expressa de duas formas diferentes, como em uma partilha desigual, quando o todo é a reunião de várias partes, sendo uma delas, ao menos, uma função de uma ou várias outras. O próprio todo é, então, uma função de função.

Esse caso junta-se àquele dos problemas com duas incógnitas, os quais são exemplo paradigmático do raciocínio algébrico, e que deveriam ser propostos aos alunos sem esperar que tenham sido esgotados os diferentes casos de equações com uma incógnita.

Uma outra sugestão, ainda, é a de propor aos alunos situações nas quais a incógnita é uma transformação, suscetível, consequentemente, de ser positiva ou negativa: pode-se, assim, dar um sentido à solução negativa de uma equação.

Dessa forma, a ideia de "longo prazo" leva ao exame cuidadoso das relações conceituais entre a aritmética e a álgebra, como também das relações entre a aritmética e a geometria, ou entre a álgebra e a geometria. Contudo, é necessário sublinhar que essas relações entre os grandes capítulos da matemática têm também sentido no "curto prazo" da aprendizagem em sala de aula, para que sejam propostas situações suscetíveis de serem realizadas pelo professor, como também para seus comentários.

\section{Um exemplo das estruturas multiplicativas}

As situações de proporcionalidade são o quadro principal de situações em que o raciocínio obriga necessariamente que se faça uma multiplicação ou uma 
divisão, ou uma sequência dessas operações. O modelo da lei de composição binária não permite identificar e avaliar como seria necessário o peso próprio das grandezas em jogo, e o fato de que as situações de multiplicação e de divisão são analisadas quase sempre como relações entre quatro termos, logo, como situações de quarta proporcional.

Nos quadros abaixo, supondo que a coluna da esquerda indique os pesos de frutas de certo tipo, e a coluna da direita os custos correspondentes, pode-se representar com o mesmo esquema de base quatro casos de proporcionalidade simples: a multiplicação, a divisão por partição (busca de um valor unitário, conhecendo-se o preço pago c e a quantidade comprada b), a divisão por quota (busca da quantidade comprada, conhecendo-se o valor unitário a e o preço pago c) e, enfim, a busca da quarta proporcional.

\begin{tabular}{|c|c|}
\hline Proporcior & de si \\
\hline $\mathrm{Mul}$ & ação \\
\hline 1 & $\mathrm{a}$ \\
\hline$b$ & ? \\
\hline
\end{tabular}

Partição

Quota

1

?

b

c

?

c

Quarta proporcional

$\begin{array}{ll}\mathrm{a} & \mathrm{c} \\ \mathrm{b} & \text { ? }\end{array}$


De fato, desde a aprendizagem da multiplicação, os alunos são levados a operações de pensamento que não se deixam reduzir a operações numéricas, mas implicam também raciocínios sobre quantidades e grandezas, um tipo precedente de análise dimensional.

Com efeito, as duas formas de relação utilizáveis no raciocínio são:

1.- as relações escalares, ou relações entre grandezas de mesma natureza, entre os pesos, por exemplo:

- "b vezes mais que 1" na multiplicação: multiplicar o preço unitário "a" por essa relação vertical, para encontrar $\mathrm{f}(\mathrm{b})$.

- ou ainda "b vezes menos que c": dividir "c" por essa relação na divisão por partição para encontrar $\mathrm{f}(1)$.

- ou ainda "b vezes mais que a", na quarta proporcional, para encontrar f(b) quando f(a) é conhecido.

Os teoremas-em-ato então empregados são todos do tipo isomorfismo de medidas $f(n x)=n f(x) \quad$ e $f(x / n)=f(x) / n$, lembrando que, neste caso, trata-se de números inteiros.

2.- As relações do tipo função entre variáveis, quando a operação escolhida intervém entre grandezas de natureza diferente; por exemplo, entre um peso e um preço a pagar (na multiplicação, para passar horizontalmente de b kg ao preço correspondente, ou da despesa c à quantidade de frutas correspondente na divisão por quota). Isto significa utilizar o coeficiente de proporcionalidade $\mathrm{k}$, que é igual a $\mathrm{f}(1)$ :

$$
f(x)=k x \quad \text { e } \quad x=f(x) / k
$$

As duas formas de raciocínio se parecem; entretanto, elas são conceitualmente muito diferentes: $k$ é um quociente de dimensões (reais por quilo), enquanto $n$ é uma relação escalar sem dimensão.

Falemos, primeiro, de "longo prazo": é principalmente em física que deverão ser desenvolvidas as relações entre grandezas diferentes, notadamente aquelas que são funções de muitas outras variáveis. A análise dimensional tornase então um recurso conceitual decisivo: o conceito de energia mecânica, o de potência em eletricidade são produtos de várias outras grandezas.

Ora, desde a escola elementar e os primeiros anos da escola secundária (até 14 ou 15 anos), os alunos conhecem também produtos de dimensão (as medidas espaciais, área e volume), como também quocientes de dimensões (a velocidade, as densidades de diversos tipos, a massa volúmica). Outros exemplos importantes, na aritmética do cotidiano, são a produção e o consumo em função do número de pessoas e do período do tempo.

Falemos, agora, de "curto prazo", tomando um exemplo relativo exatamente ao consumo. E consideremos as formas de mediação às quais o professor pode recorrer; trata-se, no exemplo que segue, de fazer com que os alunos 
tomem consciência da estrutura da proporcionalidade dupla. Eis o exemplo, experimentado e observado no último ano da escola elementar: ${ }^{5}$

Os alunos preparam a temporada em uma colônia de férias de inverno e devem calcular as quantidades de comida necessárias para 50 crianças durante 28 dias. Em um documento, eles se informam que são necessários 3,5 quilos de açúcar por semana para 10 crianças.

Eles se empenham, então, em tentativas de cálculo mais ou menos complicadas: consumo por dia e por criança, cálculo da quantidade levando em conta somente o período de tempo, ou somente o número de crianças, e outras tentativas. Uma criança, no fundo da sala (vamos chamá-la de Vitor), levanta-se então e diz: "É fácil! 5 vezes mais, 4 vezes mais, tudo isto faz 20 vezes mais!". Primeira observação: essa criança emprega uma propriedade das funções bilineares, a qual não lhe foi ensinada, e que pode ser analisada da seguinte maneira:

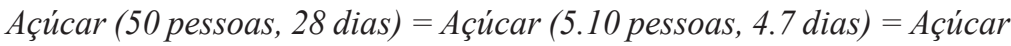
5.4 (10 pessoas, 7 dias).

Ou de forma mais refinada $f(5.10,4.7)=5.4 f(10.7)$.

É caso particular do teorema das funções bilineares:

$$
f\left(k_{1} x_{1}, k_{2} x_{2}\right)=k_{1} \cdot k_{2} f\left(x_{1}, x_{2}\right)
$$

Segunda observação: as formulações que acabamos de expor não estão, evidentemente, ao alcance dos alunos de final da escola elementar. Logo, impõese a pergunta: como o professor poderá explicitar o raciocínio de Vitor? Para os outros alunos e para o próprio Vitor?

A fórmula $S=k P$.J é ainda mais complexa que o raciocínio precedente; aliás, ela se apoia nesse raciocínio e em considerações também muito delicadas: A quantidade de açúcar é proporcional ao número de pessoas quando o periodo de tempo é constante;

Ela é proporcional ao periodo de tempo quando o número de pessoas é mantido constante;

As duas variáveis "número de crianças" e "período de tempo" são independentes.

Logo, a quantidade de açúcar é proporcional ao produto.

A tabela de dupla entrada abaixo permite que se possam levar em conta essas propriedades de forma mais clara.

5 No sistema de ensino francês, o último ano da escola elementar tem alunos de 10 anos de idade, aproximadamente. 
Proporcionalidade simples em relação ao número de crianças (leitura horizontal, linha por linha).

Proporcionalidade simples em relação ao período de tempo (leitura vertical, coluna por coluna).

Diagrama comutativo das relações " 5 vezes mais" e "4 vezes mais" na parte interna da tabela, para a variável quantidade de açúcar.

Naturalmente, não é suficiente uma situação, nem uma só sessão de comentários sobre essa situação e sobre o gráfico correspondente para que os alunos compreendam a proporcionalidade dupla; mas essa representação simbólica tem grandes virtudes ao representar as duas proporcionalidades e sua independência, justamente graças às propriedades do significante espacial bidimensional. Ainda, esta é uma forma de representação pré-algébrica. Ela tem uma função de mediação. Lembremo-nos que Vygotsky evocava dois "papéis" distintos em relação ao processo de mediação: aquele do professor e aquele do simbolismo.

\section{TABELA DE DUPLA PROPORCIONALIDADE}

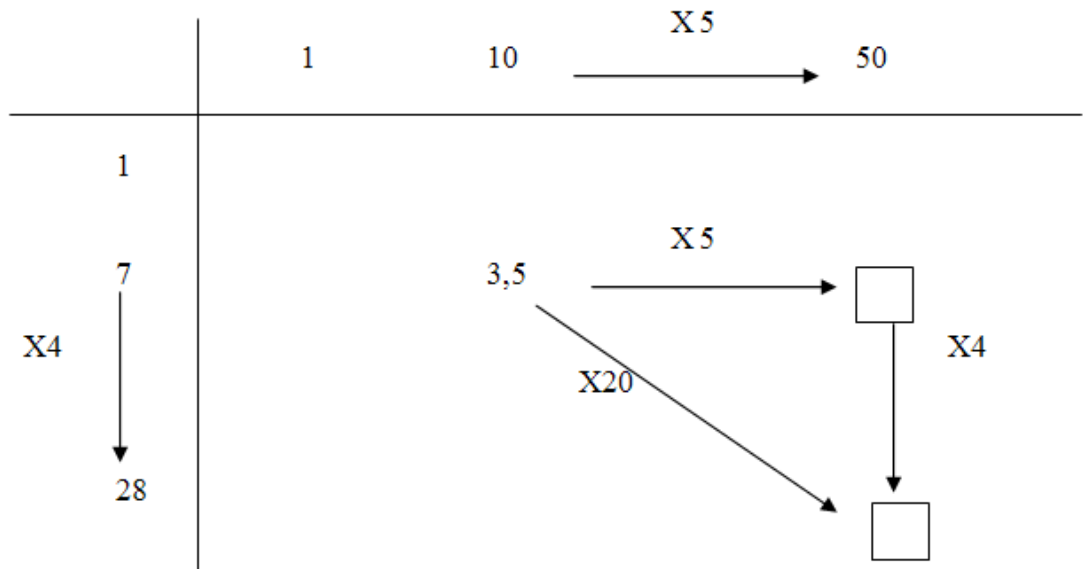




\section{O que concluir?}

O conceito de esquema é essencial porque ele designa formas de organização da atividade para classes de situações bem identificadas e circunscritas. $\mathrm{O}$ par teórico situação/esquema deve então substituir o par estímulo/resposta, de um behaviorismo estreito ao extremo; o par sujeito/objeto, embora inevitável, é ele próprio muito geral para permitir estudos empíricos precisos. No entanto, esse privilégio teórico do par situação/esquema não deve fazer com que se subestime o papel da linguagem e de outras formas simbólicas na conceitualização e na comunicação, incluindo-se, nesse caso, também, a comunicação didática. $\mathrm{O}$ professor é um mediador essencial, evidentemente, mas seu papel não se limita a acompanhar a atividade dos alunos, tutelando-os: a presente contribuição tenta mostrar que, na profissionalização do professor, são essenciais as duas funções, a da escolha das situações a serem propostas aos alunos, e a da representação de sua estrutura conceitual por meio de formas simbólicas acessíveis.

\section{BIBLIOGRAFIA COMPLEMENTAR EM PORTUGUÊS E EM CASTELHANO}

GROSSI, E. P. (Org.). Por que ainda há quem não aprende? A teoria. Petrópolis: Vozes, 2003.

MOREIRA, M.; CABALLERO, C.; VERGNAUD, G. La teoria de los campos conceptuales y la enseñanza/aprendizaje de las ciencias. Burgos: Universidad de Burgos, 2009. (Estudios y Monografias).

MORO, M. L. F.; SOARES, M. T. C. (Orgs.). Desenhos, palavras e números: as marcas da matemática na escola. Curitiba: Editora UFPR, 2005.

VERGNAUD, G. Lev Vygotski. Pedagogo e pensador do nosso tempo. Porto Alegre: GEEMPA, 2004.

. Esquemas operatórios de pensamento: uma conversa com Gérard Vergnaud.

In: GROSSI, E. P. (Org.). Ensinando que todos aprendem. Fórum Social pelas Aprendizagens. Porto Alegre: GEEMPA, 2005. p. 85-100. 
. A contribuição da psicologia nas pesquisas sobre a educação científica, tecnológica e profissional do cidadão. In: FÁVERO, M. H.; CUNHA, C. da (Orgs.). Psicologia do conhecimento: o diálogo entre as ciências e a cidadania. Brasília: UNESCO: Instituto de Psicologia da Universidade de Brasília: Líber Livros Editora, 2009a. p. 39-60.

. A criança, a matemática e a realidade. Tradução de: MORO, M. L. F. Curitiba: Editora UFPR, 2009b.

. O que é aprender? In: BITTAR, M.; MUNIZ, C. A. (Orgs.). A aprendizagem matemática na perspectiva da teoria dos campos conceituais. Curitiba: Editora CRV, 2009c. p. 13-36. 
